\title{
Public Engagement and Sustainable Energy Development
}

\author{
Ellen S. Gilliland ${ }^{1 *}$, Emily A. Sarver ${ }^{1}$, Leigh-Anne H. Krometis ${ }^{2}$ and Michael Karmis ${ }^{1}$ \\ ${ }^{1}$ Department of Mining and Minerals Engineering, Virginia Tech, Blacksburg, VA, USA \\ ${ }^{2}$ Department of Biological System Engineering, Virginia Tech, Blacksburg, VA, USA
}

\begin{abstract}
Public engagement is increasingly important in ensuring the success of projects related to energy development, particularly with regard to issues of environmental protection, public health, and socio-economic impacts. This is due to concurrent trends in public behavior, including a rise in public interest in these projects that is not matched by a rise in science literacy, and increasing organization and participation of the public through social media, citizen science, and grassroots initiatives. In recent years, several high-profile incidents have demonstrated that when public concern is ignored or met with a passive response from industry, it can rapidly grow into organized opposition that negatively impacts or wholly derails a project. Engaging, listening to, and educating stakeholders during early planning and development phases are therefore essential to earning credibility and trust. Moreover, maintaining two-way lines of communication throughout the lifespan of a project demonstrates social responsibility and facilitates cooperation, acceptance, and even support from communities and others. Positive experiences with specific projects at a local, community level can influence the larger public opinion of an entire industry sector. This paper presents cases studies of public engagement related to shale gas development (including hydraulic fracturing and pipeline construction), mountaintop removal mining, and management of mixed-use watersheds near surface mining operations. The experiences highlighted in these case studies are used to draw best practices of public engagement for sustainable energy development.
\end{abstract}

Keywords: public engagement, social license, shale gas, fracking, pipelines, mountaintop removal mining, watershed management

\section{Introduction}

Within the scientific research community, the importance of public engagement has gained increasing recognition. In a 2007 article in Nature, medical researcher, Patrick Taylor, stated that public engagement has both "gone viral" and "gone global" and has the ability to make real impacts to research (Taylor 2007). Nancy Baron, the science outreach director for COMPASS, an organization providing communications training for scientists, provides further evidence for the increasing focus on engagement, including shifting attitudes observed during her own experience as a communications coach and documented in surveys, the recent inclusion of communication and engagement activities in academic tenure review, and the surge of workshops, materials, and other resources available on the subject (Baron 2016). In addition to COMPASS, a number of organizations and institutes have been developed to train scientists for communication and engagement with the public, perhaps most notably the Alan Alda Center for Communicating Science at Stony Brook University, and academic fellowship programs, such as the Leopold Leadership Program at Stanford University and the Wilburforce Fellowship Program, have been established for the same purpose.

The need to engage with the public extends to industry as practitioners of scientific research and technology. Within the energy sector, engagement is especially important for issues related to environmental protection, public health, and socio-economic impacts. These issues tend to elicit concern and opposition from the public, who are more organized than ever through social media, citizen science, and grassroots initiatives. If ignored, public opposition can negatively impact or derail industry projects related to energy development. As one reader stated in a letter to Nature, "[p]ublic [skepticism] about science, compounded by poor communication, is standing in the way of implementing sustainable technologies that could solve pressing global issues, such as the provision of sufficient clean energy, water and food" (Slippers 2013). Another related issue is the lack of science literacy among the public. Anita Makri, a writer and mentor with the New York Academy of Sciences, explains that when the public lacks the tools and capacity to understand science, "emotions and beliefs that pander to false certainties become more credible" (Makri 2017). The benefits of engagement may be easy to underestimate when considered for an individual project, but success at a smaller, community level can positively impact the larger industry. Similarly, failure at the community level can hurt the larger industry and possibly perpetuate misinformation or fuel larger opposition. Overcoming communication obstacles and knowledge gaps through effective public engagement is critical to ensuring the success of individual, community-

* Corresponding Author: E.S. Gilliland, elleng @ vt.edu, phone: +1 540-2312258

Copyright $\odot 2017$ Canamaple Academia Services, http://press.camdemia.ca

DOI: 10.15273/gree.2017.02.034 
level projects and to supporting the future of sustainable energy development.

Industry groups, however, could face challenges in connecting with the public who may be less receptive to messages from the corporate versus scientific communities. A 2010 survey conducted by sister publications, Scientific American and Nature, asked participants to rate their level of trust of different groups of people as sources of accurate information on a scale of 1 (strongly distrust) to 5 (strongly trust) (In Science We Trust: Poll 2010). Scientists scored the highest level of trust out of all groups, averaging 3.98, while companies averaged a score of only 1.78 , squarely in "distrust" territory. It is difficult to estimate the degree to which distrust of companies may be influenced by a lack of corporate engagement to date. Additional groups scoring higher than companies include friends or family, nongovernmental organizations (NGOs), citizen groups, and journalists. The survey was limited to the magazines' readership and, therefore, not representative of the general public, but it still provides a strong indication that industry groups wishing to engage the public will find their messages in competition with those from a number of variably-informed sources.

Industry groups pursuing engagement in order to earn approval for their projects or operations, often called "social license" to operate, face a daunting challenge: how? Baron refers to the gap between interest in communicating with the public and successful engagement as the "valley of death" (Baron 2016). Many engagement practices utilized and recommended by the scientific research community are transferable to industry groups and are summarized below.

- Collect input from the public. Questions should be specific and address existing perceptions, concerns, and anticipated impacts to quality of life (Taylor 2007). This recommendation implies first defining a role for the public and identifying objectives for communication that produce actionable public input.

- Earn trust. This is an overarching goal to all communications that is served by all engagement activities. However, trust is earned most directly through these key, interrelated practices:

- Demonstrate transparency. The challenge of transparency is described as "owning up to [uncertainties] while still maintaining authority" (Makri 2017). In addition to addressing uncertainties in their work, scientists should disclose (and limit) any conflicts of interest, including corporate, political, or financial interests (In Science We Trust 2001, Taylor 2007). Failure to be upfront and forthcoming can cause the public to doubt the competence of scientists or infer bias, undermining trust.

- Build credibility. This practice aligns with transparency but involves demonstrating foresight of and plans to manage unintended or "runaway" consequences (Taylor 2007). It also involves understanding the values held by the public and using them to connect and communicate more meaningfully with them (Resolve to Engage 2017). Baron cites studies by Dudo and Besley (2016) and Fiske and Dupree (2014) showing that the educational approach researchers often favor in communicating with the public is not consistent with "willingness to listen" on the part of the public, which is instead related to "how likeable, warm and authentic they find the speaker" (Baron 2016).

- Educate. Improving science literacy builds the capacity to understand information, accept scientific uncertainties, and, ultimately, trust the work of scientists (In Science We Trust 2001, Makri 2017). Education also involves correcting misinformation and fake or misleading news (Taylor 2007, Resolve to Engage 2017).

- Be creative. Taylor emphasizes a need to be "continuously creative" in public engagement and supports the simultaneous use of multiple approaches which could include polls or surveys, face-to-face meetings with the public, or written correspondence (Taylor 2007). Incorporating science-related imagery into outreach materials and communications may be beneficial, as participants in a recent survey indicated higher responsiveness to science imagery compared to text (Bucchi and Saracino 2016).

- Use social media. The role of social media has become so significant in society that, while it could be considered a tool for conducting the engagement practices above, it warrants distinction as a fundamental practice itself. Experts stress the importance of social media as resource for learning about engagement and as a platform to engage with the public, promote science literacy, and correct misinformation from other sources (Baron 2016, Resolve to Engage 2017).

Recent examples of public engagement related to energy development are considered in the following sections in order to demonstrate the benefit of implementing engagement practices or the cost of failing to. The experiences highlighted in these examples are used to draw additional best practices for corporate-public engagement to support sustainable energy development.

\section{Missed Opportunities in Shale Gas Development: Fracking and Natural Gas Pipelines}

Much of the American public supports the use of natural gas for energy production and heating from the environmental perspective that it is cleaner-burning than other fossil fuels such as coal or oil. Yet a sizeable segment of the population objects to aspects of natural gas development, especially the practice of hydraulic fracturing, or "fracking," of tight shale reservoirs, despite its critical role in keeping gas costcompetitive with other fuels. A 2016 Gallup poll revealed that a majority of 51 percent of Americans are opposed to fracking, an increase from 40 percent the previous year (Swift 2016). Nearly a decade after fracking first became a matter of public controversy, the shale gas industry has yet to issue an organized response to the still-growing opposition of the practice.

Science supports several environmental advantages to fracking that could resonate with the public. Combined with lateral drilling technology, fracking dramatically reduces the surface footprint of natural gas development by allowing 
more gas to be produced from each well and reducing the number of wells required to develop a gas field. Estimates of surface impacts related to well drilling show that traditional, vertical drilling impacts an area on the surface that represents approximately 10 percent of the areal extent of the subsurface reservoir, while the combined technologies of fracking and multi-lateral drilling used for shale gas development provide a reduced impact of only 0.7 percent (Energy in Depth 2012). In response to public pressure, the U.S. Environmental Protection Agency (EPA) recently conducted a national-scale assessment of the potential impacts to drinking water posed by fracking. In a draft report of the results, the EPA states there is no evidence for "widespread, systemic impacts" from fracking to date (EPA 2015). Activities related to shale gas development have been linked to felt seismicity, notably in Oklahoma and Ohio, but this is correlated almost exclusively with the injection of wastewater in deep disposal wells (Keranen et al 2014, Walsh and Zoback 2015, Kim 2013); a common misconception that the seismicity is caused by fracking, perpetuated by many reputable media outlets (e.g., see Conca 2016, Fischetti 2012, Wattles and Egan 2016), has not been corrected by the industry, despite the fact that a fracking ban would halt gas production while a ban on deep wastewater injection would not. An additional misconception is that shale gas fields could continue to be developed in the U.S. without fracking, but enhanced reservoir permeability achieved by fracking is the key to producing gas at economic rates. Natural gas production in the U.S. relies on fracking, and the environmental benefits of using natural gas for energy production are significant. Global energy-related $\mathrm{CO}_{2}$ emissions rates calculated by the International Energy Agency (IEA) showed no increase during the years 20132015, while economic growth continued, marking a significant decoupling of the two trends (IEA 2016). U.S. energy-related $\mathrm{CO}_{2}$ emissions declined by two percent in 2015, due primarily to conversion from coal- to gasgenerated electricity (IEA 2016).

Another aspect of natural gas development that generates opposition is the construction of natural gas pipelines. The growing demand for natural gas in the U.S. is matched by a need for new gas infrastructure, and pipelines are considered the safest and most reliable way to transport large volumes of gases or liquids (PHMSA-DOT 2017a). Pipelines must pass inspections at federal and state levels and are regulated under the Code of Federal Regulations (CFR), Title 49: Subpart B-Chapter 1, which requires that operators of pipelines near "high consequence areas" - determined by factors including proximity to people, surface and drinking waters, and/or ecological resources, depending upon the type of pipelinedevelop pipeline integrity managements programs which must be re-evaluated and updated annually (PHMSA-DOT 2017b). However, large-scale, organized protests focused largely on perceived environmental and safety risks of natural gas pipelines have compromised the development of new infrastructure in several locations. Demands from pipeline protest groups are often extreme, aimed at stopping the construction of new pipelines rather moving them to areas of lesser impact. Halting pipeline construction, however, would not halt gas production or usage; instead, natural gas would be compressed or liquefied and transported on roadways and, in limited parts of the U.S., by rail. These options have their own safety risks, related to the extreme pressures and temperatures required for storage and the increase in tractortrailer traffic. Additionally, some perceived safety risks of natural gas pipelines may be unfounded or inflated. Some pipeline objectors believe, falsely, that transmission and distribution pipelines carry frack fluid. From 1997-2016, the average number of annual pipeline-related fatalities was 16 and most serious incidents involving pipelines were classified as due to "excavation damage" or "other outside force damage" (PHMSA-DOT 2017c), suggesting that the limited, immediate risks lie in construction-related activities and are possibly preventable. Additional perspective may be gained by considering that much of the public accepts the risks of using natural gas for home heating, cooking, and certain appliances, although national statistics show that natural gas, specifically, is the source of almost 8,000 home fires annually (Hall 2014), including more than 30 civilian fatalities, and surely contributes to a number of the annual $400+$ fatalities from non-fire-related carbon monoxide poisoning (CDC 2014).

The natural gas industry has missed an opportunity to engage and educate the public - and, in some cases, correct the record - on concerns related to natural gas development. The passive reaction of industry to large-scale public opposition perpetuates an impression that industry does not share the values or concerns about environmental and human safety held by the public, and industry has lost credibility and trust as a result. Perhaps a telling indication of this is that the Sierra Club, a prominent environmental organization which once strongly supported the development of natural gas resources to replace coal, now states that "as we phase out coal, we need to leapfrog over gas" (Sierra Club 2017).

\section{Self-Branding as Self-Sabotage: Fracking and Mountaintop Removal Mining}

The use of the term "fracking" to refer to hydraulic fracture treatments of tight oil or gas reservoirs originated with the oil and gas industry itself. It is often suggested that the term sounds violent or crass, and some language experts support the idea that the relationships we make between the form and the meaning of words is not arbitrary but sound-symbolic (Perniss et al 2010, Nuckolls 1999). A well-known example of sound-symbolism is the "bouba/kiki effect," which refers to a now-famous experiment in which participants were shown two abstract shapes and given two names, "bouba" and "kiki," to assign to them (Ramachandran and Hubbard 2001). An overwhelming 95 percent of participants named the more angular, spiky shape "kiki" and the smoother, rounder shape "bouba." Many members of the public who oppose fracking also agree that the term sounds offensive and exploit this sound-symbolism to fuel opposition and market fracking as an assault on the earth. By inventing the term, industry essentially handed the public this ammunition.

A similar case from the mining industry relates to "mountaintop removal mining," a name which also originated within its industry. Mountaintop removal mining 
(MTR) has encountered tremendous opposition from environmentalists in the Appalachian region where it is practiced as a surface coal mining method. Here, local populations consider the mountains central to their way of life. The name is descriptive of the operation but gives an exaggerated impression of the impact as extreme and permanent. When an MTR operation is complete, operators are required under Title 30: Chapter VII of the CFR to 1) return the land surface to its approximate original contour (AOC) within 50 feet and provide revegetation or 2) convert the land to a higher, alternative use, such as a recreational area (CFR 2017). The same regulations also require that operators post reclamation bonds prior to operating to ensure land reclamation will be conducted regardless of whether the mining operation is successful. Mountaintop removal mining does have an environmental impact where it is conducted, but it is not as devastating or permanent as images that the name may conjure of eternally decapitated mountains.

It is difficult to estimate the impact that the industryderived terms, "fracking" and "mountaintop removal mining," have had on public concern and opposition. Reactions from environmentalists might not have been so passionate if the practices had been given names that were descriptive and accurate but less provocative-perhaps "flow stimulation" or "flow-stim" instead of "fracking" or "high topographic mining" instead of "mountaintop removal mining." The natural gas and mining industries failed to anticipate reasonable reactions and concerns from the public to their inhouse terminology. In these cases, the inability to understand and connect with the public on their values not only hurt the industries' credibility and trust with the public, but also motivated the opposition. Underlying these shortcomings may be a larger failure on the part of the industries to anticipate that the public would even encounter these terms, suggesting a greater ignorance for the role of public engagement.

\section{Management of Mixed-Use Watersheds Near Surface Mining: Untapped Potential}

The Appalachian region of the U.S. represents a juxtaposition of valuable natural resources. With expansive coal reserves, and now accessible natural gas, the region is a significant contributor to the nation's energy supply. Additional resource development includes metallurgical coal for both domestic and international steel production and forest products for a range of end uses. On the other hand, Appalachia is recognized as global biodiversity hotspot, with its mountain streams and terrain supporting a plethora of aquatic organisms and wildlife. Scientific efforts to characterize relationships between water quality and anthropogenic stressors in this region have focused on the impacts of extractive industries, and have largely ignored other known sources of contamination. The Appalachian region has long suffered from widespread socio-economic depression (ARC 2011), which has manifested in a variety of outcomes, including inadequate infrastructure and public services for municipal water distribution and sanitation. The management of mixed-use watersheds, such as those impacted by mining and residential communities, therefore, represents a regionally-unique challenge that lies at the practical intersection of economic, social, and environmental domains.

Surface mines typically have large footprints, which can lead to significant surface water quality impacts via discharge of sediment, metals, acid or base, or dissolved solids. Elevated dissolved solids (generally approximated with specific conductivity) downstream from mining activities has become a serious concern in Appalachia due to detrimental effects on aquatic organisms (e.g., see Merricks et al 2007, Pond et al 2008, Cormier et al 2013). However, insufficient or non-existent sewage treatment in many isolated communities (Glasmeier and Farrigan 2003, Gasteyer and Vaswani 2004) presents additional downstream concerns, including water quality and ecosystem impacts as well as public health risks.

The industrial discharges from surface mining are highly regulated under the U.S. Clean Water Act through permitting, monitoring and enforcement activities. However, residential discharges of household wastewater, while locally recognized, are rarely addressed (Cook et al 2015) due to limited economic resources, challenging geological constraints, impractical sewage treatment requirements, and insufficient characterization of the impacts of sewage discharges. The result is that management many of mixed-use watersheds in Appalachian is likely insufficient because efforts are focused almost unilaterally on one source of impairment while another source, associated with human health risk, is largely neglected.

This issue of mixed-use watershed management in Appalachia represents an opportunity for corporate-public engagement that is especially meaningful because of the potential direct involvement of both industrial and community stakeholders. It has been suggested that proper identification and engagement of these various, specific stakeholders is paramount to developing and supporting effective watershed management solutions with long-term viability (Cook et al 2015). Key groups in this case necessarily include industry members, regulatory agencies and technical experts, but participation and buy-in of local community members, municipalities, and NGOs is also critical. The power of a strong stakeholder network here is in the ability to creatively align resources in order to solve the problems at hand. Collectively, the network includes cultural resources (i.e., contextual knowledge of how surface waters are valued and used), technical resources (i.e., capabilities for identification of the bases for conflict between various water uses, and feasible solutions), economic resources (i.e., the means for implementing solutions), and governance (i.e., the procedural framework for implementing solutions). In a few cases, the veracity of diverse stakeholder engagement has been demonstrated for the management of mixed mining and residential use watersheds (e.g., Cassell and Cantrell 2000). But, given that such circumstances can be found all across Appalachia, significant potential exists for further progress. 


\section{Discussion and Best Practices of Public Engagement for Sustainable Energy Development}

The experiences of public engagement described in the sections above have important implications for sustainable energy development. Several examples demonstrate the considerable cost industry pays by not engaging the public on their concerns or correcting misinformation; the public can grow to oppose industry practices that support objectives for environmental protection and human health and safetyobjectives the public generally values - when industry does not explain or defend them. Some sectors of the energy industry face an especially difficult path to meaningful engagement because, in addition to the lack of trust the public has for companies in general, the negative perceptions and "scare stories" surrounding some energy development practices (which industry has passively allowed to propagate) resonate more with the public than data or information that may come along to negate them (In Science We Trust 2001). A point of encouragement, however, is the clear evidence for widespread public interest in issues related to energy development, which suggests that if industry provides attractive opportunities, the public may engage genuinely on these issues and could potentially serve a supportive role through social media or citizen science initiatives. An overarching message from these experiences echoes an observation made by Taylor that "[p]ublic involvement is inevitable, whether invited or not" (Taylor 2007). By extension, it is important for the energy industry to recognize that 1) it participates in public engagement regardless of its intent to, and 2) that engaging intentionally and meaningfully is its best opportunity to shape the conversation that will exist surrounding its practices and support existing and new efforts toward sustainable development.

The experiences described in the sections above also suggest additional best practices for public engagement. Unlike those considered previously, which support efforts to improve general understanding among the public of sciencerelated topics, these more specifically support corporatepublic engagement on specific industry practices or projects at a community level. These additional best practices are designed to complement, not replace, those described previously and are summarized below.

- Engage early. Early efforts should focus on listening to and learning from the public about their values and concerns in order to proactively address them before a new project impacts their community. Earning the social license to operate in advance of a project supports smoother operations throughout its lifespan.

- Implement an engagement plan. Set and share expectations for communication with the public, including a communications schedule. Adherence to the plan will build credibility with the public. Although a company may find success in developing and repeating certain engagement models, an engagement plan should be tailored to the unique community involved, including its needs and values, and can be adapted over time as the needs of both the project and community change.
- Maintain a presence. Continuous, active participation in engagement activities with the public is key to retaining social license throughout the lifespan of a project. Frequent communication with the public will help to ensure continued support and present opportunities to openly discuss unexpected outcomes before they become problems.

- Build a strong stakeholder network. A welldeveloped network of invested stakeholders adds resources for problem-solving beyond those within an individual company. Stakeholder groups should be diverse and include all relevant players.

- Partner with researchers and scientists. Because it has been suggested that the public puts more trust in scientists than in companies (In Science We Trust: Poll 2010), consider involving researchers and scientists in a project (in roles that involve direct engagement with the public) to establish or restore credibility.

- Exercise thoughtful self-branding. The development of in-house terminology related to industry practices should anticipate eventual public awareness and reaction. Thoughtfully-developed terminology can be accurate and not invite unwarranted controversy.

- Consider broader impacts. In conducting a costbenefit analysis for public engagement related to an individual project, consider risks and impacts beyond the project- and community-levels. Anticipate the consequences of a positive or negative experience for the larger industry and public.

- Facilitate citizen science. Where resources and interest are sufficient, community stakeholders can be trained to participate in certain project tasks related to environmental monitoring and data collection, promoting a sense of personal investment in the project outcome.

\section{Conclusions}

The role of public engagement in energy development is especially important for issues related to environmental protection, public health, and socio-economic impacts, which tend to elicit concern stemming from community fears. Success or failure to engage meaningfully and build trust on these issues at a community level can have significant impacts on both the project at hand and the industry on a wider scale. Recent examples of public engagement related to shale gas development and mountaintop removal mining demonstrate the consequences of failing to engage with or anticipate reactions from the public, including the loss of credibility and trust, the perpetuation of misinformation about industry practices and their safety, and even the potential to further motivate public opposition. These examples convey the need for early, intentional engagement by industry that includes frequent communication, adaption to changing community needs, and anticipation of broader impacts beyond the scope of an individual project or community. An additional case study of mixed-use watershed management for residential communities near surface mining highlights the opportunity for industry and community stakeholders to combine resources in order to implement sustainable solutions for community and environmental 
health. A set of best practices, specifically for public engagement by industry, have been drawn from these varied experiences. In combination with established practices from the science community, these recommendations for corporate-public engagement can be used to build positive public relations and support projects related to sustainable energy development.

\section{Acknowledgements}

The authors wish to thank energy companies around the world that choose to invest in sustainable practices and improve the communities in which they operate. The authors would like to thank the Appalachian Research Initiative for Environmental Science (ARIES) for funding a portion of this work. Views expressed here represent those of the authors and not necessarily funding sources.

\section{References}

ARC (Appalachian Regional Commission), 2011. Economic overview of Appalachia 2011. https://www.arc.gov/research/researchreportdetails.asp? REPORT_ID $=124$.

Baron, N., 2016. So you want to change the world? Nature: Comment, 540: 517 - 519.

Bucchi, M. and B. Saracino, 2016. "Visual science literacy": Images and public understanding of science in the digital age. Science Communication: Commentary, 1-8. DOI: $10.1177 / 1075547016677833$

Cassell, B. and S. Cantrell, 2000. Imboden community wastewater treatment project. Management Academy for Public Health: Chapel Hill, NC, USA.

CDC (Centers for Disease Control and Prevention), 2014. Quick stats: Average annual number of deaths and death rates from unintentional, non-fire-related carbon monoxide poisoning by sex and age group - United States, $\quad 1999 \quad-2010$. https://www.cdc.gov/mmwr/preview/mmwrhtml/mm63 03a6.htm.

CFR (Code of Federal Regulations), 2017. Title 30: mineral resources, chapter VII: office of surface mining reclamation and enforcement, Department of Interior. http://www.ecfr.gov/cgi-bin/ECFR?page=browse.

Conca, 2016. Thanks to fracking, earthquake hazards in parts of Oklahoma now comparable to California. https://www.forbes.com/sites/jamesconca/2016/09/07/t he-connection-between-earthquakes-andfracking/\#16a6c0c96d68.

Cook, N., E. Sarver and L. Krometis, 2015. Putting corporate social responsibility to work in mining communities: Exploring community needs for central Appalachian wastewater treatment. Resources, 4: 185 - 202. DOI: 10.3390/resources 4020185

Cormier, S.M., Suter, G.W., L., Zheng and G.J. Pond, 2013. Assessing causation of the extirpation of stream macroinvertebrates by a mixture of ions. Environmental Toxicology and Chemistry, 32(2): 277 - 287. DOI: 10.1002/etc.2059
Energy in Depth, 2012. Vertical and horizontal well development examples: Estimated surface disturbance. http://www.energyindepth.org.

EPA (U.S. Environmental Protection Agency), 2015. Assessment of the potential impacts of hydraulic fracturing for oil and gas on drinking water resources executive summary. https://cfpub.epa.gov/ncea/hfstudy/recordisplay.cfm?de id $=244651$.

Fischetti, 2012. Ohio earthquake likely caused by fracking wastewater. Scientific American (online). https://www.scientificamerican.com/article/ohioearthquake-likely-caused-by-fracking/.

Gasteyer, S. and R. Vaswani, 2004. Still living without the basics in the 21st century: Analyzing the availability of water and sanitation services in the United States. Rural Community Assistance Partnership, Washington, DC.

Glasmeier, A.K. and T.L. Farrigan, 2003. Poverty, sustainability, and the culture of despair: Can sustainable development strategies support poverty alleviation in America's most environmentally challenged communities? Annals of the American Academy of Political and Social Science, 590: 131 - 149.

Hall, J.R., 2014. Fires starting with flammable gas or flammable or combustible liquid. National Fire Protection Association Report. http://www.nfpa.org/news-and-research/fire-statisticsand-reports/fire-statistics/fire-causes/chemical-andgases/fires-starting-with-flammable-gas-or-flammableor-combustible-liquid.

IEA (International Energy Agency), 2016. Decoupling of global emissions and economic growth confirmed. https://www.iea.org/newsroom/news/2016/march/decou pling-of-global-emissions-and-economic-growthconfirmed.html.

In Science We Trust [Editorial], 2001. Nature Medicine, 7: 871. DOI: $10.1038 / 90866$

In Science We Trust: Poll Results on How You Feel about Science [Editorial], 2010. Scientific American (online). https://www.scientificamerican.com/article/in-sciencewe-trust-poll/.

Keranen, K.M, M. Weingarten, G.A. Abers, B.A. Bekins and S. Ge, 2014. Sharp increase in central Oklahoma seismicity since 2008 induced by massive wastewater injection. Science, 345(6195): 448 - 451. DOI: $10.1126 /$ science. 1255802

Kim, W., 2013. Induced seismicity associated with fluid injection into a deep well in Youngstown, Ohio. Journal of Geophysical Research, 118(7): 3506 - 3518. DOI: 10.1002/jgrb.50247

Makri, A., 2017. Give the public the tools to trust scientists. Nature: World View, 541: 261. DOI: 10.1038/541261a

Merricks, T.C., D.S. Cherry, C.E. Zipper, R.J. Currie and T.W. Valenti, 2007. Coal-mine hollow fill and settling pond influences on headwater streams in southern West Virginia, USA. Environmental Monitoring and Assessment, 129(1): 359 - 378. DOI: 10.1007/s10661006-9369-4 
Nuckolls, J., 1999. The case for sound symbolism. Annual Review of Anthropology 28: 225 - 252. DOI: 10.1146/annurev.anthro.28.1.225.

Perniss, P., R.L. Thompson and G. Vigliocco, 2010. Iconicity as a general property of language: Evidence from spoken and signed languages. Frontiers in Psychology. 1 - 227. DOI: $10.3389 /$ fpsyg.2010.00227.

PHMSA-DOT (Pipeline and Hazardous Materials Safety Administration-U.S. Department of Transportation), 2017a. Pipeline basics. https://primis.phmsa.dot.gov/comm/PipelineBasics.htm ?nocache $=9202$.

PHMSA-DOT (Pipeline and Hazardous Materials Safety Administration-U.S. Department of Transportation), 2017b. Briefing: Integrity management. https://primis.phmsa.dot.gov/comm/IM.htm?nocache $=6$ 194.

PHMSA-DOT (Pipeline and Hazardous Materials Safety Administration-U.S. Department of Transportation), 2017c. Pipeline incident 20 year trends (Database). https://www.phmsa.dot.gov/pipeline/library/datastats/pipelineincidenttrends.

Pond, G.J., M.E. Passmore, F.A. Borsuk, L. Reynolds and C.J. Rose, 2008. Downstream effects of mountaintop coal mining: comparing biological conditions using family and genus-level macroinvertebrate bioassessment tools. Journal of the North American Benthological Society, 27(3): 717 - 737. DOI: 10.1899/08-015.1.

Ramachandran, V.S. and E.M. Hubbard, 2001. Synaesthesia: a window into perception, thought, and language. Journal of Consciousness Studies, 8(12): 3 - 34.

Resolve to Engage in 2017 [Editorial], 2017. Nature, 541: 5. DOI: $10.1038 / 541005 a$.

Sierra Club (website), 2017. Why move beyond natural gas? http://content.sierraclub.org/naturalgas/why-movebeyond-natural-gas.

Slippers, B., 2013. Young scientists: public engagement should start early. Nature: Correspondence, 498: 299. DOI: $10.1038 / 498299$ d.

Swift, A., 2016. Opposition to fracking mounts in the U.S. gallup http://www.gallup.com/poll/190355/oppositionfracking-mounts.aspx.

Taylor, P.L., 2007. Rules of engagement. Nature: Commentary, 450: 163 - 164. DOI: 10.1038/450163a.

Walsh, F.R. and M.D. Zoback, 2015. Oklahoma's recent earthquakes and saltwater disposal. Science Advances, 1(5): e1500195. DOI: 10.1126/sciadv.1500195.

Wattles, J. and M. Egan, 2016. Oklahoma orders shutdown of 37 wells after earthquake. CNN Money (online). 